\title{
An Exploration of Communicating with Textspeak - A Social Presence Perspective
}

\author{
Ying Chieh Liu \\ Department of Information Management, Chaoyang University of Technology \\ 168, Jifeng E. Rd., Wufeng District, Taichung, 41349, Taiwan \\ Email: allanliu@cyut.edu.tw \\ www.cyut.edu.tw \\ Chad Lin \\ Centre for Behavioural Research in Cancer Control, Curtin University \\ Curtin Health Research Campus, 10 Selby Street, Shenton Park, WA 6008, Australia \\ Email: elin123au@yahoo.com.au \\ www.curtin.edu.au \\ Yu-An Huang \\ Department of International Business Studies, National Chi Nan University \\ University Road, Puli, Nantou 545, Taiwan \\ Email: yahuang788@gmail.com \\ www.ncnu.edu.tw
}

\begin{abstract}
With proliferous usage in CMC (Computer-Mediated Communication), textspeak (such as $\mathrm{c} u$ means see you) has become common words appears in email, SMS, IM, Blog and Twitter. Little research has explored how textspeak affects people's intimacy when interacting through CMC tools. Thus, this study investigates whether social presence carried by textspeak affects people's interaction. The results indicate that social presence is positively related to social interaction, which implies that people feel more intimate and the existence of others by using textspeak. The discussions and future directions are discussed.
\end{abstract}

Keywords: Textspeak, Social presence, Social interaction, Communication

\section{Introduction}

Textspeak can be categorized by acronyms, emoticons and omission of redundant words and vowels. ${ }^{1}$ It is a shortening of language to fit into short number of characters and often be applied in an informal context. For example, ":)" means happy, "ack" means acknowledge, "gtg" means got to go, "ttyl" means talk to you later. ${ }^{2}$
Textspeak has appeared in many CMC (ComputerMediated Communication) environments, including email, IM (Instant Messenger), Blog and twitter. Scholars doubted that using textspeak may have negative effects on literacy skills. For example, Murphy and Lebans ${ }^{3}$ applied Web 2.0 tools in a secondary school teaching and found that textspeak may deteriorate students' writing literacy. Drouin and Davis 
1 studied 80 university students on the relationships between textspeak usage and literacy ability. More than half of students considered textspeak hinder their literacy ability although the statistics showed that textspeak was not related to low literacy performance. Nevertheless, with the increasing usage of $\mathrm{CMC}$ technology in the modern society, textspeak is an inevitable trend.

We are interested in how the usage of textspeak affects people's interactions and relationships when they communicate through CMC. Social presence is applied to formulate the hypothesis, and data collection is engaged in four train stations in Taiwan in order to examine the hypothesis. SEM (Structural Equation Modelling) is used to construct the measurement and structural model. The discussion is presented at the end.

\section{Social Presence}

Short, Williams, and Christie $^{4}$ were credited with developing social presence theory which explains the effects of mediated communication by the aspect of social cues. Social presence is defined as "the degree of salience of the other person in the interaction and the consequent salience of the interpersonal relationships." 4 Rourke, Anderson, Garrison and Archer $^{5}$ identified social presence as three categories and twelve indicators. Three categories include affective, interactive and cohesive, and present the contexts of observable social behaviors. However, Tu and $\mathrm{Mclsaac}^{6}$ argued that social presence is more complicated than previous thought and they developed four dimensions and twenty-three variables to measure social presence. The four dimensions include social context, online communication, interactivity and privacy. From their studies, it can be seen that the nature of social presence focuses on how people disclose themselves, communicate and build relationships.

Social presence was seen as a media's property that determines how people interact and communication. Earlier studies suggested that CMC is unable to transmit the perception of co-presence due to $\mathrm{CMC}$ weakens the sense of counterparts who are dispersed geographically (see Ref.7). Latter researchers started to question whether the properties of CMC tools determine their social presence and argued that people's sense of social presence is more important than the capabilities of media (i.e., Refs. 8, 9). However, recent studies have identified social presence as an important factor in CMC environments, such as discussion boards and video conferencing ${ }^{6,10,11}$. According to Walther ${ }^{12}$, a text-based communication still transfers people's feeling by clues hidden in texts and emoticons. This implies that people are able to feel other's existence through social cues carried by CMC and can feel a "real person in mediated communication." 8

\section{Hypothesis Development}

Yoon $^{13}$ found that social behaviors accounted for 26.3 percent of the group performance of virtual learning teams. When people sense no social presence in a CMC environment, they feel impersonal and this leads the results of less amount of information shared between them $^{16}$. Social presence creates inclusion (establish identity with others), affection (develop relationships with others), trust, self-disclosure, and a warm and approachable environment. ${ }^{5,15}$

A study by Gunawardena and $\mathrm{Zittle}^{8}$ indicated that people who feel higher degree of social presence would strengthen their socio-emotional experience by using emoticons to express missing nonverbal cues in written forms. A study by Tu and McIsaac ${ }^{6}$ also concluded that the higher level of social presence results in the increasing level of online interaction. When people communicate through $\mathrm{CMC}$, deindividuation may occur due to the simpler environment and less social cues compared to realistic world, which results in the unrestrained behaviors and disinhibition. ${ }^{16}$

However, while people use more and more text-based CMC communication, such as email, SMS, MSN, Blog and twitter, textspeak would be utilized more frequently and extensively. Since textspeak carries social cues, we presume that social presence should be transmitted by the textspeak and it promotes social interactions among people. Thus, the hypothesis is stated below:

Hypothesis: social presence is positively related to social interaction when people are using textspeak to communicate. 


\section{Research Methodology}

\subsection{Subjects}

We adopted survey to collect data to examine the hypothesis. To extend the diversity of subjects, four train stations in Taiwan were chosen to distribute questionnaires: Taipei, Taichung, Kaoshung and Hualien, which are located respectively in North, Central, South and East of Taiwan. Six trained assistants asked the voluntary passengers who passed by train stations to fill in the designed questionnaires. Except the demographic data, the first question was to ask whether the subjects have had the experience in using textspeak in their daily life. If negative, the survey interrupted. If positive, the subjects were asked about their feeling of using textspeak in further depth. The duration of survey lasted for 4 weeks and 840 subjects in total participated. 310 participants (37\%) never used textspeak while 530 participants $(63 \%)$ did. Since this study focuses on those people who have used textspeak, 530 participants would be our analysis samples. Among them, females were slighter more than males (males: $n=237$, females: $\mathrm{n}=293$ ). The demographics are shown in Table 1.

\subsection{Measurement items}

The measurement items of questionnaire were derived from past research. Three measurement items of Social presence were revised from Burke and Chidambaram ${ }^{17}$ while three measurement items of social interaction were derived from the study by Nezlek, Richardson, Green and Schatten-Jones. ${ }^{18}$ These measurement items are shown in Table 2. Participants indicated the degree to which they agreed with each item by selecting from 7-point Likert scale, from strongly agree to strongly disagree.

\section{Analysis Results}

\subsection{Demographics}

Table 1 shows the demographic data of subjects experienced in using textspeak. It can be seen:

(i) Most people who had experience in using textspeak are young students (age range from 15 23 and accounts for $74 \%$ ) and their education levels are located from high school to bachelor $(85.5 \%)$.

(ii) People who live in South of Taiwan have higher proportion using textspeak. The plausible reason could be that we had more participants in Kaoshung train station which is located in South of Taiwan.

Table 1. Demographic data of who have used textspeak

\begin{tabular}{lllllll}
\hline Items & \multicolumn{5}{c}{ Category } \\
\hline Age & $<15$ & $15 \sim 18$ & $19 \sim 23$ & $29 \sim 35$ & $36 \sim 42$ & $>42$ \\
& 31 & 178 & 214 & 69 & 30 & 8 \\
& $(5.8 \%)$ & $(33.6 \%)$ & $(40.4 \%)$ & $(13.0 \%)$ & $(5.7 \%)$ & $(1.5 \%)$ \\
Location & North & Central & South & East & Others & \\
& 143 & 138 & 204 & 40 & 5 & \\
& $(27 \%)$ & $(26 \%)$ & $(38 \%)$ & $(7.5 \%)$ & $(0.9 \%)$ & \\
Education & Primary & Junior & High & College & Bachelor & Master \\
& 7 & high & 137 & 44 & 174 & 18 \\
& $(1.3 \%)$ & 50 & $(25.8 \%)$ & $(8.3 \%)$ & $(51.7 \%)$ & $(3.4 \%)$ \\
& & $(9.4 \%)$ & & & & \\
Career & Student & Business & Technology & Service & Public & Others \\
& 406 & 15 & 17 & 29 & Servant & 36 \\
& $(76.6 \%)$ & $(2.8 \%)$ & $(3.2 \%)$ & $(5.5 \%)$ & $27(5.1 \%)$ & $(6.8 \%)$ \\
\hline
\end{tabular}

\subsection{Validity of measurement items}

The questionnaire comprised two parts that were related to social presence and social interaction. The reliability was evaluated using Cronbach's coefficient alpha $(\alpha)$ and their $\alpha$ values were all above 0.70 , which indicated a reliable measurement instrument (social presence $\alpha$ $=0.81$; social interaction $\alpha=0.80$ ). Moreover the ranges of all factor loadings and the measurement errors were acceptable and significant at alpha $=0.001$, which provided evidence of convergent validity. Table 2 shows the results of employing Confirmatory Factor Analysis (CFA) using the method of maximum likelihood. 
Table 2. Measurement items, factor loading, error, SMC

\begin{tabular}{|c|c|c|c|c|}
\hline $\begin{array}{l}\text { Construct } \\
\text { (source) }\end{array}$ & Measurement items & $\begin{array}{l}\text { Factor } \\
\text { loading }\end{array}$ & Error & SMC \\
\hline \multirow[t]{3}{*}{$\begin{array}{l}\text { Social } \\
\text { presence } \\
\alpha=0.81\end{array}$} & $\begin{array}{l}1 \text { I can express my } \\
\text { feelings when used } \\
\text { textspeak }\end{array}$ & 0.73 & 0.23 & 0.55 \\
\hline & $\begin{array}{l}2 \text { I feel textspeak is } \\
\text { humanistic }\end{array}$ & 0.70 & 0.26 & 0.60 \\
\hline & $\begin{array}{l}3 \text { I can transmit my } \\
\text { message by using } \\
\text { textspeak }\end{array}$ & 0.74 & 0.22 & 0.65 \\
\hline \multirow[t]{3}{*}{$\begin{array}{l}\text { Social } \\
\text { interaction } \\
\alpha=0.80\end{array}$} & $\begin{array}{l}1 \text { Textspeak can create } \\
\text { intimacy between my } \\
\text { friends and me }\end{array}$ & $0 . .60$ & 0.29 & 0.56 \\
\hline & $\begin{array}{l}2 \text { I feel close when I read } \\
\text { others' textspeak }\end{array}$ & 0.58 & 0.29 & 0.54 \\
\hline & $\begin{array}{l}3 \text { I feel it is interesting } \\
\text { when I read others' } \\
\text { textspeak }\end{array}$ & 0.53 & 0.38 & 0.43 \\
\hline
\end{tabular}

\subsection{Model building}

Structural Equation Modeling (SEM) was utilized to estimate the relationships between social presence and social interaction using LISREL 8.72. This study selected six criteria to evaluate model fitness by integrating the recommendations of Bagozzi and Youjae ${ }^{19}$ and Jöreskog and Sörbom ${ }^{20}:$ X2/degree of freedom, RMSEA (Root Mean Square Error of Approximation), CFI (Comparative-fit index), IFI (Incremental Fit Index), GFI (Goodness-of-fit index) and AGFI (Adjusted Goodness of fit index). Table 3 shows the resulting fit indexes and indicates good model fit. The overall fit of the proposed structural model was quite satisfactory $\left(\chi^{2}\right.$ $=1.65, \mathrm{df}=8, \mathrm{p}=0.97, \mathrm{RMSEA}=0.00, \mathrm{CFI}=1.00$, $\mathrm{IFI}=1.00, \mathrm{GFI}=1.00, \mathrm{AGFI}=1.00$ ).

Table 3. Model fitness indices of the research model

\begin{tabular}{cccc}
\hline Statistics & $\begin{array}{c}\text { Recommended } \\
\text { value }\end{array}$ & $\begin{array}{c}\text { Obtained } \\
\text { value }\end{array}$ & $\begin{array}{c}\text { Test of } \\
\text { fitness }\end{array}$ \\
\hline $\mathrm{X}^{2}$ & -- & 1.65 & -- \\
$\begin{array}{c}\text { Degree of } \\
\text { freedom }\end{array}$ & -- & 8 & -- \\
$\mathrm{X}^{2} / \mathrm{df}$ & $<3$ & 0.23 & Good \\
P-value & & 0.97 & Good \\
RMSEA & $<0.06$ & 0.00 & Good \\
CFI & $>0.95$ & 1.00 & Good \\
IFI & $>0.95$ & 1.00 & Good \\
GFI & $>0.90$ & 1.00 & Good \\
AGFI & $>0.90$ & 1.00 & Good \\
\hline
\end{tabular}

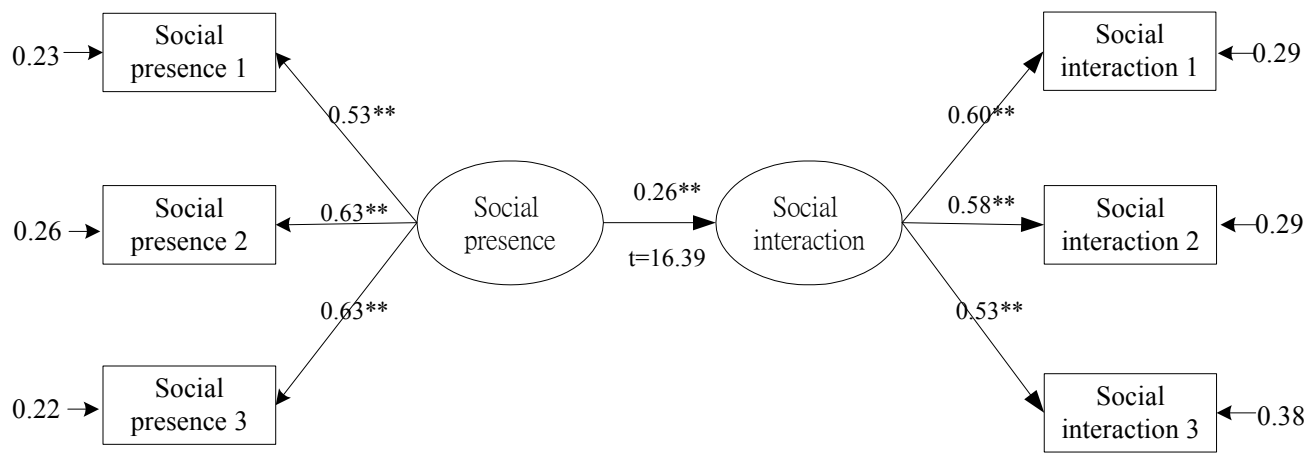

Fig. 1. SEM model

Figure 1 shows the measurement and structural model of social presence and social interaction. The coefficient between social presence and social interaction is 0.26 $(t=16.39)$. This shows the coefficient is significant at alpha $=0.001$, which presents that social presence is significantly related to social interaction. Thus, the hypothesis is supported. It can be inferred that social presence can be transmitted by texpseak, and social interactions can be enhanced by the existence of social presence. 


\section{Discussions and Conclusions}

The results provided the evidence of that people feel intimate by using textspeak, and this improves their interactions and social relationships. We concluded that textspeak is able to increase individuals' presence and let others feel they are communicating with a real person. The precious humanity is transferred by acronyms and emoticons.

Our results corresponded to the Hyperpersonal theory ${ }^{12}$. When senders engage in the process of selecting acronyms and emoticons to express themselves, they are identifying who they are and the receivers recognize them from the attributions of paralingual cues in the message. This process is enriched with asynchronous exchanges, letting both sides have enough time to deliberate the messages received and sent. Texspeak also helps the senders express themselves better than face-to-face interaction in a certain degree, due to the voidance of embarrassment or interpersonal pressure, and the receivers can understand more about the senders. Thus, textspeak interaction would be a bonus for the development of normal personal relationships.

Our results highlight the importance of textspeak for the practitioners of CMC tools and social sites, like email, IM, blog and twitter. Supporting textspeak in the system can encourage users to express themselves more and better, and it creates a rich and colorful communication environment. It can also benefit the revenue of practitioners. Like the popular communication tool "Line", their cute emoticons (including animations and pictures) bring the company competitive advantages.

Additionally, we also found that individuals may have their unique way of using textspeak to identify themselves. For example, some people may prefer emoticons to express their feeling; some impatient people may often use acronyms even create their own ones. However, this deserves more investigation for future scholars.

\section{References}

1. M. Drouin and C. Davis, R u txting? Is the use of text speak hurting your literacy?, J. Literacy Res. 41 (2009) 46-67.
2. D. Crystal, A glossary of netspeak and textspeak (Edinburgh University Press, Edinburgh, 2004).

3. J. Murphy and R. Lebans, Unexpected outcomes: Web 2.0 in the secondary school classroom, Int J. Tech Teach Learn. 4(2) (2008) 134-147.

4. J. Short, E. Williams and B. Christie, The social psychology of telecommunications (Wiley, London, 1976)

5. L. Rourke, T. Anderson, D. R. Garrison and W. Archer, Assessing social presence in asynchronous text-based computer conferencing, J. Dist Educ. 14(2) (1999) Retrieve

from http://www.jofde.ca/index.php/jde/article/view/1536.

6. C. -H. Tu and M. McIsaac, The relationship of social presence and interaction in online classes, Am J Dist Educ. 16(3) (2002) 131-150.

7. J. B. Walther, Interpersonal effects in computer-mediated interaction: A relational perspective, Comm Res. 19(1) (1992) 52-90.

8. C. N. Gunawardena and F. J. Zittle, Social presence as a predictor of satisfaction with a computer-mediated conferencing environment, Am J. Dist Educ. 11 (1997) 826.

9. T. Anderson, L. Rourke and D. R. Garrison, Assessing teaching presence in a computer conferencing context, $J$. Async Learn Network. 5(2) (2001) 1-17.

10. B. D. Homer, J. L. Plass and L. Blake, The effects of video on cognitive load and social presence in multimedia-learning, Comput Hum Behav. 24(3) (2008) 786-797.

11. H. -J. So and T. A. Brush, Student perceptions of collaborative learning, social presence and satisfaction in a blended learning environment: Relationships and critical factors, Comput Educ. 51(1) (2008) 318-336.

12. J. B. Walther, Computer-mediated communication: Impersonal, interpersonal, and hyperpersonal interaction, Hum Comm Res. 23(1) (1996) 3-43.

13. S. W. Yoon, Examination of member behaviors, group processes and development shaping forces of virtual learning teams (Unpublished doctoral dissertation, Department of Human Resource Education, University of Illinois, Urbana-Champaign, 2003)

14. A. S. C. Leh, Computer-mediated communication and social presence in a distance learning environment, Int $J$. Educ Telecomm. 7(2) (2001) 109-128.

15. J. Weisberg, D. Te'eni and L. Arman, Past purchase and intention to purchase in e-commerce: The mediation of social presence and trust, Internet Res. 21(1) (2011) 8296.

16. E. -J. Lee, Deindividuation effects on group polarization in computer-mediated communication: The role of group identification, public-self-awareness, and perceived argument quality, J. Comm. 57(2) (2007) 385-403.

17. K. Burke and L. Chidambaram, A longitudinal examination of media characteristics and group outcomes, MIS Quarterly. 23(4) (1999) 557-580. 
18. J. B. Nezlek, D. R. Richardson, L. R. Green and E. Schatten-Jones, Psychological well-being and day-to-day social interaction among older adults, Pers Relat. 9 (2002) 57-71.

19. R. P. Bagozzi and Y. Youjae, On the evaluation of structural equation models, J. Acad Market Sci. 16(1) (1988) 74-94.

20. K. G. Jöreskog and D. Sorbom, PRELIS 2: User's reference guide (Scientific Software International, Chicago, 1996). 